\title{
The scenario of presentation of young females in a rural cancer hospital of North India: An initial experience
}

\author{
Vivek Tiwari, Piyush Shukla', Gourav Gupta²
}

\begin{abstract}
A total of $5 \mathrm{I}$ cases of young females aged between 18-35 years were prospectively studied for the presentation in a Rural Charitable Cancer hospital in north India during the period August $201 \mathrm{I}$ to April 20 I 2. Breast related symptoms comprised 27 (52.94\%) cases, out of which 10 (19.60\%) were proven malignant. Other cases seen were Gynecological (Gyn) 8 (I5.68\%), Head and Neck (H and N) 5 (9.80\%), Gastrointestinal (GI) 4 (7.84\%), Lymphomas $3(5.88 \%)$ and $2(3.92 \%)$ cases each of Bone Tumors and Central Nervous System (CNS) tumors. Breast related symptoms constituted the major presentation in young females (aged I8-35 years) in our Rural Cancer Hospital. This high percentage of Breast related symptoms points towards the increasing trend of Breast malignancies possibly overtaking cancer cervix in rural India, as already in the urban settlements of India as well as the increasing awareness in the females of rural India regarding early symptoms of carcinoma Breast.
\end{abstract}

Key words: Breast carcinoma, rural cancer hospital, rural, young females

\section{Introduction}

The widening economic, regional and gender disparities in India are posing challenges for the health sector. About $75 \%$ of health infrastructure, medical man power and other health resources are concentrated in urban areas where $27 \%$ of the population lives. ${ }^{[1]}$ There have been an estimated 555,000 deaths due to cancer in India in the year 2010. ${ }^{[2]}$ This study was conducted in a rural cancer hospital over a period of nine months from August 2011 to April 2012 to better understand the common presentations in young females (rural) to a cancer hospital.

\section{Results}

Of the 51 young females presenting to our center, the

Department of Radiation Oncology, MIMS, Rewari, Haryana, 'All India Institute of Medical Sciences, ${ }^{2}$ Rajiv Gandhi Cancer Hospital and RC, Delhi, India

Correspondence to: Dr. Vivek Tiwari,

E-mail:dr_vivektiwari@rediffmail.com

\begin{tabular}{|l|l|}
\hline \multicolumn{2}{|c|}{ Access this article online } \\
\hline Quick Response Code: & Website: \\
\hline & www.sajc.org \\
\cline { 2 - 2 } & \\
\hline
\end{tabular}

maximum (37.25\%) belonged to the $18-25$ years subgroup [Figure 1].

In the whole group of 51 young females, $28(54.90 \%)$ were suffering from benign conditions and $23(45.09 \%$ had a malignancy [Figure 2].

A comparison of the patients presenting with breast symptoms with that of the Gyn symptoms is as shown in Figure 3.

Breast related symptoms were the chief presentation (52.94\%) followed by Gyn symptoms (15.68\%). H and $\mathrm{N}$ presentations were $9.80 \%$ and others constituted $19.60 \%$ of the presentations [Figure 4].

Breast lump was the most common (35.29\%) complaint, whereas 6 patients $(11.76 \%)$ were presented as proven cases of Invasive carcinoma Breast. 3(5.88\%) patients presented with complaints of nipple discharge [Figure 5].

Of the 27 females presenting with breast symptoms, $17(62.96 \%)$ were diagnosed with benign breast conditions while $10(37.03 \%)$ were malignant. Of the 17 benign breast conditions, $15(88.23 \%)$ comprised of clinically palpable breast lumps, while $2(11.76 \%)$ had the complaints of nipple discharge.

The 10 malignant cases comprised of $6(60 \%)$ breast lumps, $3(30 \%)$ ulceroproliferative(UP) lesions and $1(10 \%)$ case with the presenting complaint of nipple discharge [Figure 6]. 


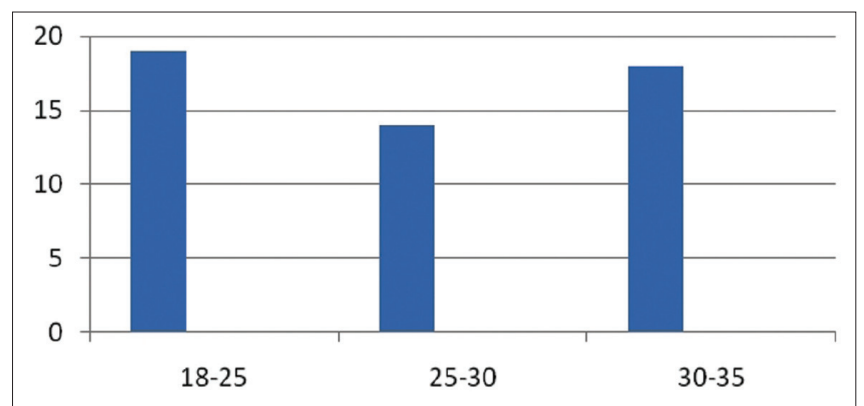

Figure 1: Age distribution of the presenting females

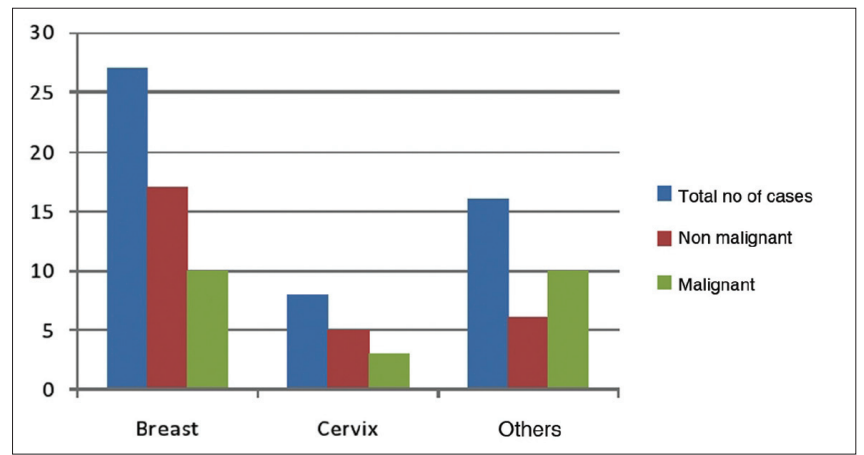

Figure 3: Symptom wise comparison of cases

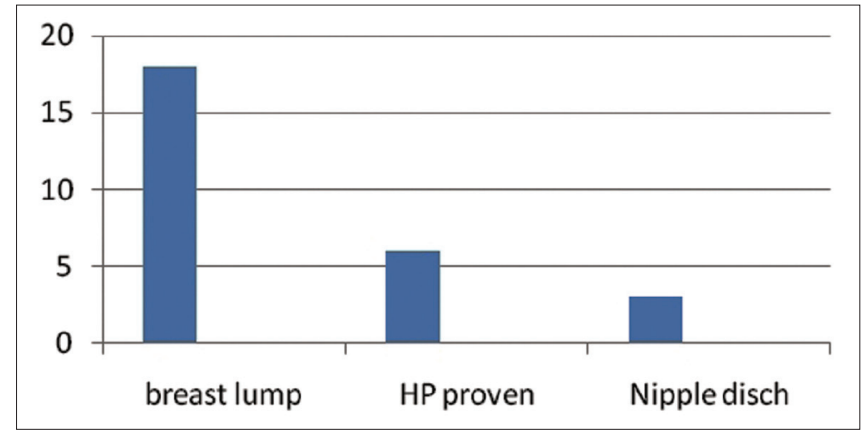

Figure 5: Distribution of Breast symptoms

Out of the $8(15.6 \%)$ cases presenting with gynecological complaints, $6(75 \%)$ had abnormal vaginal bleeding as the chief complaint while $2(25 \%)$ had abnormal vaginal discharge. other associated complaints were pain abdomen, malaise, loss of appetite. Invariably all the females were anemic.

$\mathrm{H}$ and $\mathrm{N}$ cases accounted for $5(9.80 \%)$ of cases. Out of these, three cases $(60 \%)$ were proven cancers (one of tongue and 2 of buccal mucosa.) whereas two patients (40\%) presented with clinically palpable neck nodes. Out of these two cases, one was diagnosed as tubercular lymphadenitis, whereas the other patient did not follow up.

\section{Discussion}

There is an increasing trend in rates of breast cancer in the urban population of the country A unique feature is that

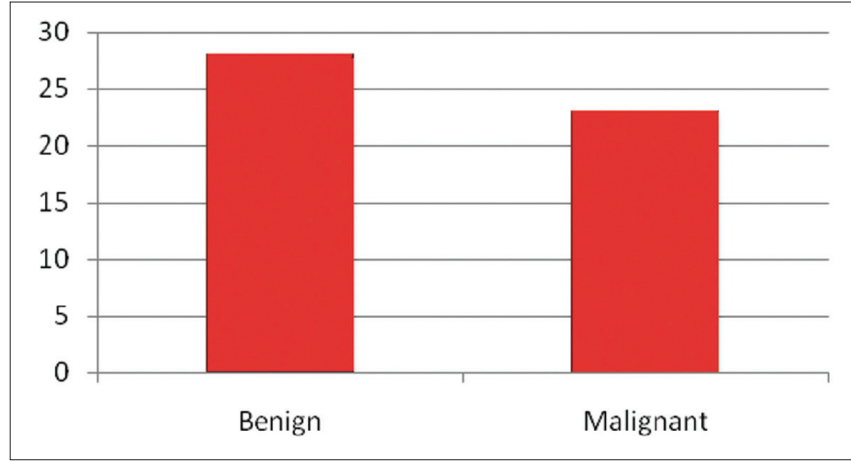

Figure 2: Distribution of cases (benign versus malignant)

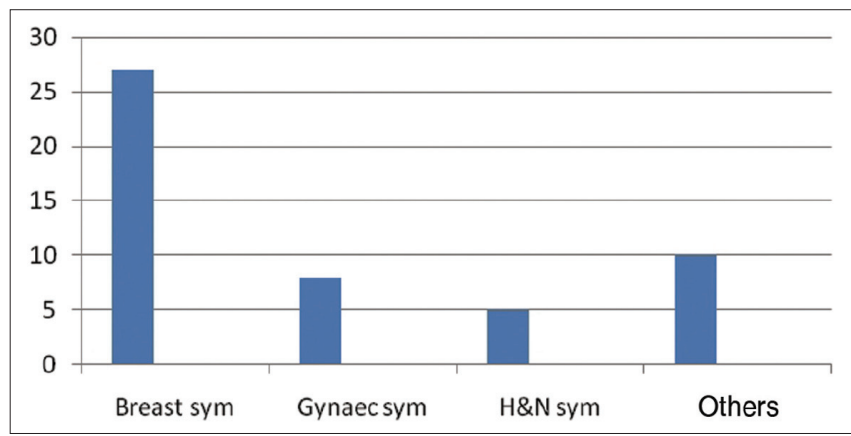

Figure 4: Symptom wise distribution of cases

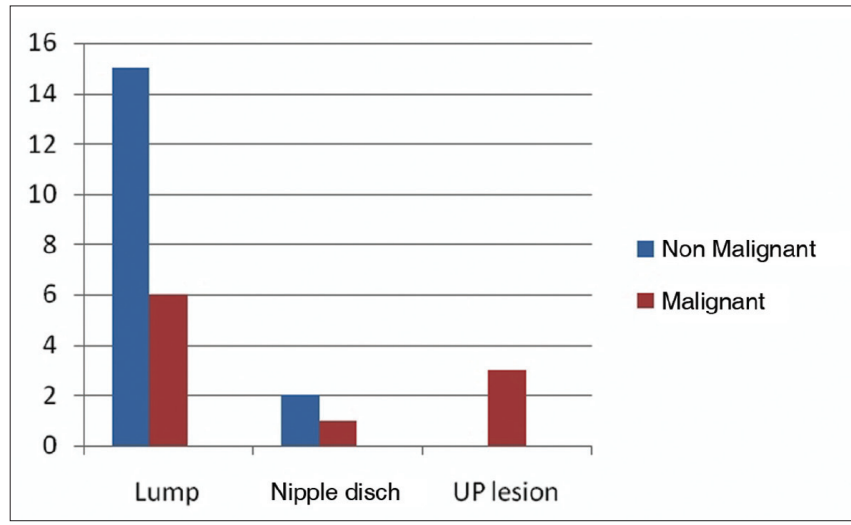

Figure 6: Comparison of symptom-wise distribution (breast)

the mean age is less than 50 years lower than that in the developed countries. ${ }^{[3]}$ However in the present study, we observed a similar trend in our rural population as well. This is in tune with the data from the National cancer registry program, which also suggests that in India the rates of cervix cancer are decreasing while breast cancer is on the increase. ${ }^{[4]}$ Trends in breast, cervix uteri, corpus uteri and ovarian cancers in six population based cancer registries (Mumbai, Bangalore, Chennai, Delhi, Bhopal, and Barshi) have shown a decreasing trend for cancer of the cervix and increasing trends for cancers of breast, ovary and corpus uteri. ${ }^{[5]}$ In the age group 15-29, Cancers of female genital organs, breast, and leukemia are most common in females in India. ${ }^{[6]}$ This study has been performed to understand the chief presentation among the young rural females. 
Because women themselves detect most breast tumors, most studies have focused on demographic or psychosocial characteristics that may predispose certain women to avoid screening mammography or to delay seeking care. ${ }^{[7]}$

Proper education is an imperative tool in the battle against cancer. Men and women with no education have higher overall cancer incidence rates compared to the educated population. A high incidence of breast cancer has been observed with increasing educational levels. ${ }^{[8]}$

\section{Conclusion}

Worldwide, cervical cancer is considered to be the second commonest cancer as far as mortality and incidence is concerned and India contributes to about $20-30 \%$ of the global burden. ${ }^{[9]}$

In our study we observed a high incidence of symptoms related to breast in the age group studied. Early stage breast cancer defined as lesions of pathologically noninfiltrating or infiltrating smaller than $15 \mathrm{~mm}$ in diameter, or infiltrating smaller than $20 \mathrm{~mm}$ in diameter with negative nodes carries a favorable prognosis. ${ }^{[10]}$ The most important factor in improving the survival rates of the patients with breast cancer is early detection. A high cure rate can be expected if the condition is discovered in early stage. ${ }^{[10]}$

Early stage breast cancer is highly curable with the currently available treatment modalities. As shown by previous studies a community oriented educational intervention program emphasizing on proper technique can bring about the desirable behavioral change among women. ${ }^{[11]}$

This is an initial experience from a single rural institute. We recommend that rural cancer hospitals come together to pool data and make the information more robust so that comparisons are possible involving a large number of patients belonging to different rural regions of India. Such a firm and healthy database may provide a clearer picture regarding the changing cancer trends in rural India.

Acknowledgement MIMS, Mirpur, Rewari.

\section{References}

1. Patil AV,Somasundaram KV, Goyal RC. Current health scenario in rural India. Aust J Rural Health 2002;10:129-35.

2. Dikshit R, Gupta PC, Ramasundarahettige C, Gajalakshmi V, Aleksandrowicz L, Badwe R, et al. Cancer mortality in India: A nationally representative survey. Lancet 2012;379:1807-16.

3. Singh AA. India can do more for breast and cervical cancer control. Asian Pac J Cancer Prev 2009; 10:527-30.

4. Takiar R, Srivastav A. Timetrend in breast and cervix cancer of women in India- (1990-2003).Asian Pac JCancerPrev2008;9:777-80.

5. Yeole BB. Trends in cancer incidence in female breast, cervix uteri, corpus uteri, and ovary in India. Asian Pac J Cancer Prev 2008;9:119-22.

6. Arora RS, Alston RD, Eden TO, Moran A, Geraci M, O'Hara C, et al. Cancer at ages 15-29 years: The contrasting incidence in India and England. Pediatr Blood Cancer 2012;58:55-60.

7. Chintamani, Tuteja A, Khandelwal R, Tandon M, Bamal R, Jain S, et al. Patient and provider delays in breast cancer patients attending a tertiary care centre: A prospective study. JRSM Short Rep2011;2:76.

8. Swaminathan R, Selvakumaran R, Vinodha J, Ferlay J, Sauvaget C, Esmy PO, et al. Education and cancer incidence in a rural population in southIndia.Cancer Epidemiol 2009;33:89-93.

9. Chhabra S, Bhavani M, Mahajan N, Bawaskar R. Cervical cancer in Indian rural women: Trends over two decades. J Obstet Gynaecol 2010;30:725-8.

10. Asagoe T, Yamoto H, Nemoto A, Takada T, Shikata J, Aoki A, et al. A study on the definition of early breast cancer. Nihon Geka Gakkai Zasshi 1988;89:84-90.

11. Rao RS, Nair S, Nair NS, Kamath VG. Acceptability and effectiveness of a breast health awareness programme for rural women in India. Indian J Med Sci2005;59:398-402.

How to cite this article: Tiwari V, Shukla P, Gupta G. The scenario of presentation of young females in a rural cancer hospital of North India: An initial experience. South Asian J Cancer 2012;1:63-5.

Source of Support: Nil. Conflict of Interest: None declared.

\section{NEWS}

The American Association of Physicians from Indian Origin (AAPI) \& Global Association of Physicians of Indian Origin (GAPIO) have joined hands with the

Ministry of Overseas Indian Affairs, Govt of India

to organize the Global Health Summit, at International Convention Center, Cochin, Kerala

from $1^{\text {st }}$ to $3^{\text {rd }}$ January 2013 (www.aapighsindia.org)

Chief Guest is Hon'ble Health Minister of India, Shri Gulam Nabi Azad.

For oncology track participation, please contact

Dr. Purvish M Parikh at purvish1@gmail.com or purvish@purvishparikh.com or +919821097752 or +919869425694. 